\title{
MAKING A DIFFERENCE: THE TALE OF RECYCLING EFFORTS OF AN INDIVIDUAL STAFF MEMBER AT AN HBCU
}

\author{
Alice E. Stephens \\ Department of Mass Media Arts, Clark Atlanta University (USA)
}

\begin{abstract}
In the area of sustainability individual efforts matter and can make a difference in the commitment of institutions of higher education for sustainable actions and practices by moving the needle closer to the goal of going green. Research supports the notion that one person can make a difference.

Institutions of higher education have the potential to function as change agents for sustainability (Stephens, Hernandez, Roman, Graham \& Scholz, 2013). According the University Leaders for a Sustainable Future sustainability implies that the critical activities of institutions of higher education are ecologically sound, socially just, and economically viable. These institutions can function as sustainable communities, embodying responsible consumption of food and energy.

In 2010 Clark Atlanta University, an HBCU took an important step toward reversing global warming when the university's president signed the American College and University President's Climate Commitment (ACUPCC) thus joining over 600 institutions in 50 states in the United States to commit to attaining carbon neutrality. Goals were defined and outlined in the institution's Strategic Plan Initiative that set the university on a path for $20 \%$ reduction of energy consumption across the campus in five years and a doubling the campus recycling efforts by 2015 thus ensuring that sustainability issues remained an integral to the CAU experience.

This presentation explores the case of a staff initiated recycling effort at an HBCU (Historically Black College and University). It analyzes an in-depth interview with the staff member whose efforts moved from interest and concern about recycling, to membership of the university's Sustainability Council and ultimately influencing the recycling behavior of others in his unit including other staff, faculty and students. The presentation serves as an example of how one person can make a difference in sustainability initiatives, and offers insight for how recycling as a practice can be initiated and sustained at an institution of higher education in their quest to go green.
\end{abstract}

Keywords: Recycling, case study, sustainability, $H C B U$.

\section{Introduction}

In the area of sustainability individual efforts matter and can make a difference in the commitment of institutions of higher education for sustainable actions and practices by moving the needle closer to the goal of going green. Research supports the notion that one person can make a difference.

Institutions of higher education have the potential to function as change agents for sustainability (Stephens, Hernandez, Roman, Graham \& Scholz, 2013). According the University Leaders for a Sustainable Future sustainability implies that the critical activities of institutions of higher education are ecologically sound, socially just, and economically viable. These institutions can function as sustainable communities, embodying responsible consumption of food and energy.

In 2010 Clark Atlanta University, an HBCU (Historically Black Colleges and Universities) took an important step toward reversing global warming when the university's president signed the American College and University President's Climate Commitment (ACUPCC) thus joining over 600 institutions in 50 states in the United States to commit to attaining carbon neutrality. Goals were defined and outlined in the institution's Strategic Plan Initiative that set the university on a path for $20 \%$ reduction of energy consumption across the campus in five years and a doubling the campus recycling efforts by 2015 thus ensuring that sustainability issues remained an integral to the CAU experience.

Sustainability implies that the critical activities of a higher education institution are (at a minimum) ecologically sound, socially just, and economically viable, and that they will continue to be so for future generations. A truly sustainable college or university would emphasize these concepts in its 
curriculum and research, preparing students to contribute as working citizens to an environmentally sound and socially just society. The institution would function as a sustainable community, embodying responsible consumption of food and energy, treating its diverse members with respect, and supporting these values in the surrounding community.

As the nation's oldest historically black research institution, Clark Atlanta University (CAU) provides leadership in Historically Black Colleges and Universities (HBCU's) sustainability and helps to foster emerging geoscience networks. CAU is on the cutting edge advancing diversity, equity and inclusion. At CAU there are three pillars of sustainability: Social (People), Environmental (Planet) and Economic (Profits)

In 2011 a Sustainability Council was established whose membership included representatives from staff, faculty, and the student body. The mission of the council was to develop and implement a campus-wide sustainability program. The council's responsibilities included supporting the president in the implementation of the ACUPCC initiatives, being a repository of information of all university matters related to sustainability and distributing all university messages regarding sustainability as well as coordinating all university programs related to sustainability. The resultant Sustainability Plan was both comprehensive and ambitious and focused on providing leadership, research, education, community support, policies and procedures to ensure that future generations would have the resources to meet their needs. A Sustainability Coordinator was hired in 2017 to help guide sustainability efforts sharing responsibility for engaging the CAU Sustainability Council and advising the student Living Green Club.

In its 2018 Annual Sustainability Report the CAU Campus Sustainability Plan continued to be a dynamic document intended to provide a roadmap for advancing sustainability over the next five years (2018 - 23). The Plan identified leadership, organization and resources as the key ingredients for moving CAU sustainability forward. The Sustainability Plan invited feedback and creative suggestions from CAU Trustees, administration, faculty and students was considered a living document to guide sustainability efforts of the university from 2018-2023.

\section{From the one to the many: the story of one individual's recycling efforts}

Although some forms of informal recycling took place on the CAU campus, the CAU Sustainability Plan identified additional strategies for reducing and diverting $75 \%$ of the University's waste stream from landfills.

Behavioral change is one of our most important sustainability goals. Most people have already made up their minds that one person cannot make any difference in regard to recycling waste. That thinking might apply in other fields. In recycling, an individual can make a big difference when that individual effort contributes to a larger task of recycling.

\section{The question: how does one person's effort change the behavior of others?}

This study asks the question - How does one person's commitment to recycling move the needle closer for an institution of higher education to go green?

\section{The method - an in-depth interview}

In-depth interviewing is a qualitative research technique that involves conducting intensive individual interviews with one or a small number of respondents to explore their perspectives on a particular idea, program, or situation. The respondents can be asked about their experiences and expectations related to a program or situation, the thoughts they have concerning the program operation, processes and outcomes, and about any changes they perceive in themselves as a result of their involvement in the program.

A one-on-one in-depth interview was conducted with a staff person employed in a broadcast service unit of the university whose personal interest in recycling lead to membership of the university's Sustainability Council and ultimately influencing the recycling behavior of others in his unit including other staff, faculty and students.

The objective of the interview was to gain insight about how the subject's individual efforts moved from a personal interest in and commitment to recycling to involvement in the university's sustainability efforts and making a difference in the recycling program. 


\subsection{The Subject}

A one-on-one In-Depth interview was conducted with a staff person employed in the broadcast service unit of the university. This person, an African-American male in his 50's, had been with the university for more than seven years starting out as a part-time staff member before becoming full-time in the last two years. Prior to working at the university, the subject worked at two large corporations located in the city of Atlanta.

\subsection{Questions}

Structured open-ended questions were used to encourage the interviewee to share his understanding, beliefs, experience and point-of-view about recycling. Asking questions that were based on the interviewee's responses and linked to the research objectives used inductive probing. The ultimate goal was to capture what the interviewee's experience meant.

\subsection{The Interview Questions included the following:}

- What has been your experience with recycling at CAU?

- How did you become involved in sustainability at CAU?

- What were your expectations related to the recycling program at CAU?

- What are your thoughts concerning your involvement with the CAU Sustainability Council? (The program operations, processes and outcomes)

- What was most rewarding about your involvement in sustainability efforts at CAU?

\section{The Results}

\subsection{Seeing an opportunity and making a difference}

The subject described how prior to joining CAU he worked at two large companies in Atlanta that had recycling programs. When he came to CAU, he worked part-time in the broadcast service unit. Because he worked on a Gospel radio show for 2 hours a day $(5-7 \mathrm{am})$ he did not have a great deal of interaction with others. Later when his hours expanded, working from $10 \mathrm{am}-2 \mathrm{pm}$, he noticed how "used" paper was just tossed away in the trash. Making his own "Recycle" labels the subject re-purposed cardboard boxes and mail bins for recycling the used paper. He would take home the boxes/bins filled with paper after his shift and put the materials in his home recycling bin provided by his local government.

After a while he thought, "if they had a recycling program" staff would engage in recycling. He asked his colleagues who he needed to talk "to get recycling bins" and was told to "talk to someone facilities." He went over to the facilities department and asked for recycling receptacles. In less than a week facilities brought two bins, which he placed near the copy machine and outside the office in the hallway. This was 5 years ago.

When asked how the unit's recycling program was going, he said housekeeping checks and empties the bins on a daily basis. "I trust the process and hope ... " the material placed in the recycle bins including other recyclables such a cans and bottles are disposed of properly.

\subsection{When others notice your good works}

Seven years ago the subject received an email inviting him to join the CAU Sustainability Council because of his recycling efforts. The council tackled "low hanging fruit" initiatives such as the turning off of office lights when one left the office. During his tenure on the Sustainability Council, the university established a goal to LEED Silver certify all new construction nd renovations of existing building. LEED certification provides independent, third-party verification that a building is designed and built using strategies aimed at achieving high performance in the key areas of human and environmental health; sustainable site development, water savings, energy efficiency, materials selection and indoor environmental quality.

\subsection{The younger generation}

The interviewee believes that the younger generation (our students) is more committed to the ideals of "Climate Change and Saving the Planet." He believes that the Sustainability Council's plans and activities that focus on creating an "impact on the entering Freshmen classes" and developing "sustainability leaders and mentors" has been effective including activities such as participation in the Recycle Mania Case Study Competition that engage students sustainability efforts of the university. 


\section{Conclusion}

This study examined how one person can make a difference in sustainability initiatives and answered "yes" to the question can one person make a difference in the arena of sustainability by using their personal passion for recycling to change the recycling behaviors of other thus optimizing that passion in their place of employment. The paper offers insight for how recycling as a practice can be initiated and sustained at an institution of higher education in their quest to go green. It is important to remember that the three pillars of sustainability are Social (People), Environmental (Planet) and Economic (Profits). A critical component of any sustainability plan is promoting awareness among the entire University community.

\section{References}

Archer, R. S., Davis, F., Ebanks, S. C., \& Gragg, R. D. S. (2019). HBCUs Broadening Participation in Geosciences (A Journey Through InTeGrate). In Interdisciplinary Teaching About Earth and the Environment for a Sustainable Future (pp. 361-378). Springer, Cham.

Bailey, J., Pena, M. and T. Tudor (2015). Strategies for Improving Recycling at a Higher

Education Institution: A Case Study of the University of the West Indies, Cave Hill Campus, Barbados. The Open Waste Management Journal. 2015, 8, 1-11

Stephens, J. C., Hernandez, M. E., Román, M., Graham, A. C., \& Scholz, R. W. (2008). Higher education as a change agent for sustainability in different cultures and contexts. International Journal of Sustainability in Higher Education, 9(3), 317-338. 